\title{
Use and misuse of thyroid hormone
}

\author{
Duncan Jake $\underline{\text { Topliss }}^{1,2}$, MD, FRACP, Shui Boon $\underline{\text { Soh }}^{1,3}$, MBBS, MRCP
}

ABSTRACT Synthetic thyroxine has replaced animal thyroid gland extract as the preferred drug in chronic thyroid hormone replacement. Synthetic thyroxine monotherapy is used to treat overt primary and secondary hypothyroidism, and some cases of subclinical hypothyroidism. In addition, thyroid-stimulating hormone suppressive therapy with thyroxine is a component of the chronic treatment for differentiated thyroid carcinoma. Liothyronine, however, is conventionally for short-term usage, including thyroid hormone withdrawal preparation for radioactive iodine scanning and treatment of differentiated thyroid carcinoma and some cases of myxoedema coma. On very rare occasions where patients are apparently intolerant of or unresponsive to thyroxine, liothyronine may be used chronically. However, there is controversy concerning the use of alternative regimens of thyroid hormone, such as the use of thyroxineliothyronine combination and thyroid extracts. Thyroid hormone has also been misused to promote weight loss and treat 'symptomatic' biochemically euthyroid patients. There is insufficient evidence to support the use of thyroid hormone to improve treatment response in depression and severe non-thyroidal illnesses.

Keywords: combination thyroid hormone therapy, liothyronine, thyroid gland extract, thyroxine, use and misuse

\section{INTRODUCTION}

The efficacy of thyroid hormone therapy in hypothyroidism has been known for over a hundred years, since Murray's use of thyroid organotherapy in 1891.(1) Although there are various types and regimens of thyroid hormone currently available, synthetic thyroxine (T4) remains the preferred form for chronic therapy. Liothyronine (T3) also plays a role, but mainly in shortterm therapy. However, there is no clear evidence that supports the use of T4-T3 combination therapy and animal thyroid gland extract, although the use of these types of thyroid hormone therapy is not uncommon. Apart from the use of thyroid hormone in the treatment of hypothyroidism and its role in the management of differentiated thyroid carcinoma, both of which have well-proven results, thyroid hormone has been speculated to be beneficial in the management of weight loss and depression, in non-thyroidal illnesses and in alleviating symptoms of 'symptomatic' biochemically euthyroid patients. This article aims to present evidence for and against these uses and misuses of thyroid hormone therapy.

\section{TYPES OF THYROID HORMONE REPLACEMENT THERAPY}

\section{T4 therapy}

Synthetic T4 (i.e. L-T4; 3,5,3',5'-tetraiodothyronine) monotherapy is the best standard replacement therapy for patients with hypothyroidism. There is, however, no evidence that T4 treatment is beneficial in cases with suggestive symptoms but normal thyroid function tests. ${ }^{(2)}$ The dose of T4 best relates to lean body mass $(1.5-3.0 \mu \mathrm{g} / \mathrm{kg} /$ day $)$, but in routine clinical care, the usual adult dose is 100-150 $\mu \mathrm{g} /$ day. In otherwise healthy adults, an initial dose of 50-100 $\mu \mathrm{g}$ /day can be increased as necessary, after a minimum of four to six weeks (three to five half-lives), in order to obtain a serum thyroid-stimulating hormone (TSH) level of $0.5-2 \mathrm{mU} / \mathrm{L}$. In the presence of ischaemic heart disease or an increased risk of arrhythmias, the TSH target should be increased to $<5 \mathrm{mU} / \mathrm{L}$. This can be achieved by commencing $\mathrm{T} 4$ at 25-50 $\mu \mathrm{g} /$ day, and increasing this dose by $25 \mu \mathrm{g}$ /day after a minimum of four weeks. ${ }^{(3)} \mathrm{A}$ TSH level that is initially very high may take months to normalise, hence the achievement of a satisfactory free T4 level in the mid to normal range and a clinical response should be accepted over TSH normalisation for up to six months. In general, once the correct dose of T4 has been achieved, the required dose remains stable and only routine annual thyroid function test monitoring is required. However, a decrease in dose may be required if a decrease in lean body mass due to advanced age is observed. T4 should only be ingested with water and on an empty stomach in the morning (at least 30 mins before food), and concomitant medications, especially calcium and iron supplements, which may interfere with T4 absorption, should be avoided. T4 should be stored in a cool dry place, away from light.

\section{T3 therapy}

T3 (i.e. L-T3; 3,5,3'-triiodothyronine) therapy is usually restricted to transient use (20-40 $\mu \mathrm{g} / \mathrm{day})$, replacing $\mathrm{T} 4$ before radioactive iodine scanning and treatment in the management of patients with differentiated thyroid carcinoma. Since genuine intolerance of, and allergic reactions and unresponsiveness to synthetic

${ }_{1}^{1}$ Department of Endocrinology and Diabetes, The Alfred, ${ }^{2}$ Department of Medicine, Monash University, Melbourne, Australia, ${ }^{3}$ Department of Endocrinology, Changi General Hospital, Singapore

Correspondence: Prof Duncan J Topliss, Director, Department of Endocrinology and Diabetes, The Alfred, 5th Floor, Centre Block, 55 Commercial Road, Melbourne, Victoria 3004, Australia.duncan.topliss@monash.edu 
$\mathrm{T} 4$ preparations are very uncommon, the chronic use of $\mathrm{T} 3$ monotherapy is rarely necessary. T3 therapy is difficult to manage because T3 levels vary markedly throughout the day in relation to the time of ingestion (T3 has a half-life of 24 hours). It is unclear whether the nonphysiological variation of T3 levels from high to low throughout the day is without risk. In addition, as T4 levels will be low during T3 therapy, T4 levels is not indicative of thyroid status. Hence, TSH level is the best biochemical index to use in monitoring thyroid status during T3 therapy.

\section{USES OF THYROID HORMONE THERAPY Subclinical hypothyroidism}

In subclinical hypothyroidism $(\mathrm{SCH})$, the issue regarding the use of thyroid hormone replacement therapy is when, and whether, to intervene. There is general agreement that $\mathrm{SCH}$ should be treated during preconception and pregnancy, ${ }^{(4)}$ with the intent to ameliorate the increased risks of miscarriage and foetal loss associated with raised TSH during pregnancy. ${ }^{(5)}$ Although plausible, ${ }^{\left({ }^{(6)}\right.}$ the effect of thyroid hormone treatment of $\mathrm{SCH}$ on foetal neurocognitive development has not been demonstrated. ${ }^{(7)}$ Usually, if TSH is $>10 \mathrm{mU} / \mathrm{L}$ in the presence of $\mathrm{SCH}$, it is generally agreed that treatment is appropriate and likely to be of clinical benefit. ${ }^{(8)}$ However, there is no consensus about the treatment of patients with $\mathrm{SCH}$ when $\mathrm{TSH}$ is $<10 \mathrm{mU} / \mathrm{L}$. Although there is evidence of an increased rate of ischaemic heart disease in $\mathrm{SCH}$ patients with $\mathrm{TSH}<10 \mathrm{mU} / \mathrm{L}^{(9)}$ there are no randomised prospective trials of thyroid hormone therapy that demonstrate benefit. Comorbidities such as dyslipidaemia and ischaemic heart disease, as well as concomitant presence of thyroid peroxidase antibodies (which predicts progression to overt hypothyroidism at about $5 \%$ per year $\left.{ }^{(10)}\right)$, are factors that prompt the commencement of treatment rather than monitoring alone. The TSH target in the treatment of $\mathrm{SCH}$ is the same as that in overt hypothyroidism.

\section{Myxoedema coma}

As this condition is very rare, there are no randomised series examining different treatment regimens. To date, there is no consensus on the use of T4 or T3 in the management of myxoedema coma. T4 provides a steady and smooth action despite a rather slow onset, with a presumed lower risk of adverse effects such as acute myocardial infarction and cardiac arrhythmias. In contrast, T3 has a more rapid onset of action, which accounts for an apparent higher risk of adverse cardiac events. The concentration of T3 also fluctuates more between doses. However, it still has a role in the management of myxoedema coma, as the rate of peripheral conversion of T4 to T3 is compromised in all critical illnesses. Although there is controversy regarding the type of thyroid hormone used in the management of myxoedema coma, intravenous administration is preferred over the enteral route in view of the gastrointestinal hypomotility associated with severe hypothyroidism, which affects the absorption of the thyroid hormone. Intravenous T4 $500 \mu \mathrm{g} /$ day, intravenous T3 $20 \mu \mathrm{g}$ every 12 hours, or a combination of intravenous T4 200-300 $\mu$ g/day with intravenous T3 $20 \mu$ g every 12 hours, have been recommended. ${ }^{(11)}$ Higher thyroid hormone doses (i.e. $>500 \mu \mathrm{g}$ of T4/day or $>75 \mu \mathrm{g}$ of T3/day) have been associated with increased mortality. ${ }^{(12,13)}$

\section{Nontoxic goitre and benign thyroid nodules}

Since TSH is the major factor contributing to thyroid growth, it is hypothesised that the suppression of TSH by thyroid hormone will inhibit thyroid growth or even reduce thyroid volume. Studies done on euthyroid patients with multinodular goitre showed a $7 \%-32 \%$ reduction in thyroid volume after one year of TSH suppressive therapy. ${ }^{(14,15)}$ This is less efficacious than treatment by radioactive iodine therapy. ${ }^{(16)}$ Morever, discontinuation of TSH suppressive therapy leads to thyroid regrowth, ${ }^{(14)}$ and prolonged TSH suppressive therapy has deleterious effects on cardiac and bone health, leading to increased risks of atrial fibrillation and osteoporosis. ${ }^{(17)}$ Hence, thyroid hormone is usually not a recommended therapeutic option in nontoxic goitre or for benign thyroid nodules, especially in elderly patients. It is also contraindicated in patients who have thyroid autonomy, where TSH is already suppressed, as exogenous therapy may result in hyperthyroidism. The only group of patients who will benefit from thyroid hormone therapy are those who develop goitre due to elevated TSH levels, ${ }^{(18)}$ usually as a consequence of Hashimoto's thyroiditis.

\section{Differentiated thyroid carcinoma}

TSH suppression reduces the risk of major adverse events occurring during the follow-up of patients with differentiated thyroid carcinoma stage II or higher. ${ }^{(19,20)}$ Low-risk patients are recommended by the American Thyroid Association (ATA) and the European Thyroid Association (ETA) to have an initial TSH of either $0.1-0.5 \mathrm{mU} / \mathrm{L}^{(21)}$ or $<0.1 \mathrm{mU} / \mathrm{L}^{(22)}$, respectively, and a TSH of either $0.3-2 \mathrm{mU} / \mathrm{L}^{(21)}$ or $0.5-1.0 \mathrm{mU} / \mathrm{L}^{(22)}$ (by ATA and ETA, respectively) during subsequent follow-up. Initial TSH suppression to $<0.1 \mathrm{mU} / \mathrm{L}$ is recommended for intermediateand high-risk patients. High-risk, disease-free patients are recommended by ATA and ETA to have either a TSH $0.1-0.5 \mathrm{mU} / \mathrm{L}$ for $5-10$ years $^{(21)}$ or $<0.1 \mathrm{mU} / \mathrm{L}$ for 3-5 years ${ }^{(22)}$, respectively.

\section{Secondary hypothyroidism}

When hypopituitarism is the cause of hypothyroidism, TSH level cannot be used as a target. Instead, a mid- to highnormal free T4 value, regardless of TSH level, is the aim. Dose selection and adjustment frequency are the same as for primary hypothyroidism. Consideration should be given to the adequacy of other pituitary hormonal axes, in particular adrenal function. T4 replacement can lead to overt borderline hypoadrenalism due to increased steroid hormone clearance, leading to Addisonian crisis. 


\section{Special concerns in pregnancy}

Before conception and during the first trimester of pregnancy, a TSH target of less than $2.5 \mathrm{mU} / \mathrm{L}$ is recommended, while during the second and third trimesters a TSH target of up to $3 \mathrm{mU} / \mathrm{L}$ is recommended. ${ }^{(23)}$ The increased metabolism of T4 during pregnancy requires prompt adjustment of the T4 dose by $30 \%-50 \%$ once pregnancy is confirmed. A simple initial adjustment would be to add the equivalent of two daily doses per week. Further adjustments should be made according to the results of thyroid function tests, which are monitored on a monthly basis during pregnancy. The preconception dose can be resumed postpartum.

\section{MISUSE OF THYROID HORMONE Combination T4 and T3 therapy}

The combined use of T4 and T3 therapy has been examined in many small trials consisting of patients who were dissatisfied with T4 replacement alone. However, no clear clinical benefit has been identified when adequate blinding was conducted. Meta-analyses of reported trials have also not identified any benefits of combination T4-T3 therapy. ${ }^{(24)}$ It has been speculated that functional polymorphisms in type 2 iodothyronine deiodinase or thyroid hormone transporters may have a role in the minority of patients who are dissatisfied with T4 monotherapy. ${ }^{(25)}$ A recently published comprehensive review highlights that even though no benefit of combination T4-T3 therapy has been established over T4 therapy monotherapy, methodological issues were present in previous trials, hence the question of the benefit of combination T4-T3 therapy remains unresolved. ${ }^{(26)}$ The review also points out that differences in deiodinase type and activity in different tissues (e.g. between pituitary and other tissues) can result in differential tissue effects. The authors speculate that polymorphisms of deiodinase genes may influence deiodinase bioactivity and intracellular T3 concentrations, thus contributing to differences in individual responses to thyroid hormone therapy, despite similar circulating levels of T4, T3 and TSH. However, evidence against this theory has been published. ${ }^{(27)}$ We suggest that as any putative advantage of combination therapy remains unproven, the administration of combination therapy should not be routine. It should only be considered if symptoms (i.e. TSH 1-2 mU/L) persist after T4 therapy has been optimised and non-thyroidal health problems, if present, have been treated. If combination T4-T3 therapy is used, it must be appreciated that the optimal ratio of T4 to T3 remains undefined. A T3 dose of $10-20 \mu \mathrm{g}$ /day in 2-3 divided doses, with monitoring using TSH assay to regulate the dose and avoid TSH suppression, is generally used. Despite the number of clinical trials attempted thus far, this issue remains a suitable topic for a rigorously constructed clinical trial.

\section{Use of thyroid gland extract}

All thyroid hormone therapies originally used thyroid gland extract. Sheep thyroid was used by Murray in 1891. (1) Today, however, desiccated thyroid gland extract is usually of porcine origin and is often designated as 'natural thyroid'. It is produced in $\mathrm{mg}$ strengths designated in the old-style units of grain (about $60 \mathrm{mg}$ ) and contains an approximate 80 to 20 proportion of T4 to T3. One prominent manufacturer is Armour, an American meatpacker company. While appropriately manufactured desiccated thyroid gland extract is clearly an effective therapy for hypothyroidism, its use has almost been entirely replaced with synthetic T4 in mainstream medicine due to a number of reasons: (a) there are wide variations in the hormone content and potency of thyroid extracts; (28) (b) T4 monotherapy has been demonstrated to be sufficient in normalising serum T3, T4 and $\mathrm{TSH}$, since most of the circulating $\mathrm{T} 3$ is derived from T4 under normal physiological conditions; and (c) thyroid extract often produces supraphysiological levels of $\mathrm{T} 3{ }^{(29)}$ which varies more through the day than if replacement was done using synthetic T4. Therefore, it has been judged that it is easier to provide accurate, stable euthyroidism with synthetic T4 therapy than with thyroid extract, as it avoids both under-, and even subtle, overtreatment. Increasing concern and evidence regarding the potential harm of subclinical hyperthyroidism has also lent support to the use of synthetic T4. Proponents of thyroid extract promote its 'natural' origin and assert that it provides a more effective therapy, especially for the small minority of patients dissatisfied with synthetic T4 therapy due to symptoms of hypothyroidism, because it contains both T4 and T3. Interestingly, the failure of T4 monotherapy to relieve the symptoms attributed to hypothyroidism was also previously raised against thyroid extract. ${ }^{(30)}$ Symptoms seen in hypothyroidism are common in the euthyroid population, ${ }^{(31)}$ and are thus not a reliable indicator of persistent hypothyroidism. Furthermore, unlike synthetic T4 preparations, thyroid extracts have not been submitted for efficacy and safety evaluation by regulatory agencies, such as the United States Food and Drug Administration, European Medicines Agency or Australian Therapeutic Goods Administration, and are therefore not recommended. ${ }^{(32)}$

\section{Thyroid hormone as a weight loss agent}

When used to treat overt hypothyroidism, thyroid hormone therapy promotes weight loss; this is mainly due to diuresis, ${ }^{(33,34)}$ and fat mass may not change. Changes in thyroid hormone economy occur in obesity (increase in free T3 and TSH, likely mediated by leptin), ${ }^{(35,36)}$ but do not resemble the changes in hypothyroidism. Short-term weight loss in cases of obesity may be achieved using thyroid hormone therapy, but this includes a significant loss of lean body mass, ${ }^{(37)}$ including cardiac muscle, and an acceleration of the resting heart rate. ${ }^{(38)}$ Thyroid hormone treatment that produces subclinical hyperthyroidism cannot be advocated, as it will increase the risk of arrhythmias, muscle wasting, ${ }^{(39)}$ and possibly bone loss, especially in postmenopausal women. The weight loss effect of thyroid hormone therapy in 
obesity is modest, inconsistent, and of unproven efficacy and safety in the long term. ${ }^{(40)}$

\section{Thyroid hormone therapy in depression}

Since the 1960s, published studies have suggested a possible short-term benefit of T3 therapy in augmenting response to tricyclic antidepressant drug therapy. ${ }^{(41)}$ Studies of T3 therapy in combination with selective serotonin reuptake inhibitors have shown equivocal results. ${ }^{(42,43)}$ Functional polymorphism in type 1 iodothyronine deiodinase (C785T) may be associated with enhanced potentiation of the antidepressant effect of sertraline by T3. ${ }^{(44)}$ However, the role of T3 therapy in the treatment of depression remains uncertain.

\section{Thyroid hormone therapy in nonthyroidal illness}

Patients suffering from chronic illnesses have varying low levels of T3 and T4 due to a decrease in thyroid hormone synthesis, changes in the level and binding affinity of binding proteins, and/or a decrease in the deiodinative pathways of thyroid hormone metabolism. The limited trials on thyroid hormone therapy in critical illnesses in animal models or humans have not shown any benefit on mortality. ${ }^{(45)}$ The suppressive effect of thyroid hormone therapy on TSH may compromise normal recovery from low-T4 syndrome and promote excessive catabolism. No adequate large-scale trials have been conducted. One human model of nonthyroidal illness is the brain-dead organ donor. Pharmacological T3 therapy appears to function solely as a vasodilator. ${ }^{(46)}$ However, extensive literature on the use of T3 in brain-dead heart donors to improve posttransplant myocardial function, although strongly advocated, ${ }^{(47)}$ remains inconclusive. ${ }^{(48)}$ Some studies show an apparent benefit, but the interpretation of their findings is confounded by suboptimal experimental designs and other interventions such as insulin, glucose, cortisol and vasopressin.

\section{Thyroid hormone therapy in "Wilson's syndrome" and symptomatic euthyroidism}

This self-named syndrome is described as the association of common and nonspecific symptoms with normal circulating thyroid hormone levels, with a putative thyroid hormone deficiency requiring therapy using a special form of T3. It has achieved some currency via internet promotion. ATA, however, thoroughly reviewed the literature and found no evidence supporting the existence of this syndrome, ${ }^{(49)}$ which it describes as being inconsistent with known thyroid physiology, having imprecise diagnostic criteria using symptoms that are both nonspecific and prevalent in the normal population, and an incorrect definition of normal body temperature. ${ }^{(50)}$ This problem is most likely a type of functional somatoform syndrome, which should be managed by acknowledging the symptoms and seeking to alleviate them, and not by the spurious use of thyroid hormone, which has not been shown to be helpful.

\section{CONCLUSION}

Thyroid hormone therapy using synthetic T4 in overt hypothyroidism, and in specific cases of $\mathrm{SCH}$, is one of the most straightforward, effective and safe therapies in clinical medicine, and is supported by evidence-based reviews. The use of combination T4-T3 therapy, or desiccated thyroid extract is not supported, and the use of thyroid hormone therapy to shrink multinodular goitre or thyroid nodules is only indicated in the presence of an elevated TSH level. TSH suppression in the treatment of differentiated thyroid carcinoma reduces recurrences in high-risk disease, but is unnecessary in low-risk disease and when follow-up evaluation indicates a low risk of recurrence. Any additional roles for, or variations of, thyroid hormone therapy should be subjected to evaluation by clinical trials rather than be part of routine clinical practice.

\section{ACKNOWLEDGEMENTS}

This is the text of a presentation at the 10th Asia and Oceania Thyroid Association (AOTA) Meeting in Bali, Indonesia in October 2012.

\section{REFERENCES}

1. Murray GR. The life history of the first case of myxoedema treated by thyroid extract. Br Med J 1920; 1:359-360.

2. Weetman AP. Thyroxine treatment in biochemically euthyroid but clinically hypothyroid individuals. Clin Endocrinol (Oxf) 2002; 57:25-7.

3. Endocrinology Expert Group. Thyroid disorders. Therapeutic guidelines: endocrinology. Version 4. Melbourne: Therapeutic Guidelines Limited 2009: 103.

4. Abalovich M, Amino N, Babour LA, et al. Management of thyroid dysfunction during pregnancy and postpartum: an Endocrine Society clinical practice guideline. J Clin Endocrinol Metab 2007; 92 (8 Suppl):S1-47.

5. Ashoor G, Maiz N, Rotas M, Jawdat F, Nicolaides KH. Maternal thyroid function at 11 to 13 weeks of gestation and subsequent fetal death. Thyroid 2010; 20:989-93.

6. Haddow JE, Palomaki GE, Allan WC, et al. Maternal thyroid deficiency during pregnancy and subsequent neuropsychological development of the child. N Engl J Med 1999; 341:549-55.

7. Lazarus JH, Bestwick JP, Channon S, et al. Antenatal thyroid screening and childhood cognitive function. N Engl J Med 2012; 366:493-501.

8. Garber JR, Cobin RH, Gharib H, et al. Clinical Practice Guidelines for Hypothyroidism in Adults: Co-sponsored by American Association of Clinical Endocrinologists and the American Thyroid Association. Endocr Pract 2012; 11:1-207.

9. Ochs N, Auer R, Bauer DC, et al. Meta-analysis: subclinical thyroid dysfunction and the risk for coronary heart disease and mortality. Ann Intern Med 2008; 148:832-45.

10. Vanderpump MP, Tunbridge WM, French JM, et al. The incidence of thyroid disorders in the community: a twenty-year follow-up of the Whickham survey. Clin Endocrinol (Oxf) 1995; 43:55-68

11. Wiersinga WM. Adult hypothyroidism - myxedema coma (Chapter 9 section 9.9). In: Thyroid disease manager [online]. Available at: www. thyroidmanager.org Accessed December 6, 2012.

12. Hylander B, Rosenquist U. Treatment of myxedema coma - factors associated with fatal outcome. Acta Endocrinol (Copenh) 1985; 108:65-71.

13. Yamamoto T, Fukuyama J, Fujiyoshi A. Factors associated with mortality of myxedema coma: report of eight cases and literature survey. Thyroid 1999; 9:1167-74.

14. Berghout A, Wiersinga WM, Drexhage HA, Smits NJ, Touber JL. Comparison of placebo with L-thyroxine alone or with carbimazole for the treatment of sporadic nontoxic goitre. Lancet 1990; 336:193-7.

15. Cesareo R, lozzino M, Isgro MA, Annunziata F, Di Stasio E. Short term 
effects of levothyroxine treatment in thyroid multinodular disease. Endocr J 2010; 57:803-9.

16. Wesche MF, Tiel-V Buul MM, Lips P, Smits NJ, Wiersinga WM. A randomized trial comparing levothyroxine with radioactive iodine in the treatment of sporadic nontoxic goiter. J Clin Endocrinol Metab 2001; 86:998-1005.

17. Biondi B, Cooper DS. The clinical significance of subclinical thyroid dysfunction. Endocr Rev 2008; 29:76-131.

18. Svensson J, Ericsson UB, Nilsson P, et al. Levothyroxine treatment reduces thyroid size in children and adolescents with chronic autoimmune thyroiditis. J Clin Endocrinol Metab 2006; 91:1729-34.

19. McGriff NJ, Csako G, Gourgiotis L, et al. Effects of thyroid hormone suppression on adverse clinical outcomes in thyroid cancer. Ann Med 2002; 34:554-64.

20. Jonklaas J, Sarlis NJ, Litofsky D, et al. Outcomes of patients with differentiated thyroid carcinoma following initial therapy. Thyroid 2006; 16:1229-42.

21. Cooper DS, Doherty GM, Haugen BR, et al. Revised American Thyroid Association management guidelines for patients with thyroid nodules and differentiated thyroid cancer. Thyroid 2009; 19:1167-214.

22. Biondi B, Cooper DS. Benefits of thyrotropin suppression versus the risks of adverse effects in differentiated thyroid cancer. Thyroid 2010; 20:135-46.

23. Stagnaro-Green A, Abalovich M, Alexander E, et al. Guidelines of the American Thyroid Association for the diagnosis and management of thyroid disease during pregnancy and postpartum. Thyroid 2011; 21:1081-125

24. Grozinsky-Glasberg S, Fraser A, Nahshoni E, Weizman A, Leibovici $\mathrm{L}$. Thyroxine-triiodothyronine combination therapy versus thyroxine monotherapy for clinical hypothyroidism: meta-analysis of randomized controlled trials. J Clin Endocrinol Metab 2006; 91:2592-9.

25. Wiersinga WM. Do we need still more trials on T4 and T3 combination therapy in hypothyroidism? Eur J Endocrinol 2009; 161:955-9.

26. Biondl B, Wartofsky L. Combination therapy with T4 and T3: towards personalized replacement therapy in hypothyroidism? J Clin Endocrinol Metab 2012; 97:2256-71.

27. Appelhof BC, Peeters RP, Wiersinga WM, et al. Polymorphisms in type 2 deiodinase are not associated with well-being, neurocognitive functioning, and preference for combined thyroxine/3,5,3'-triiodothyronine therapy. J Clin Endocrinol Metab 2005: 6296-9.

28. Rees-Jones RW, Rolla AR, Larsen PR. Hormonal content of thyroid replacement preparations. JAMA 1980; 243:549-50.

29. Penny R, Frasier SD. Elevated serum concentrations of triiodothyronine in hypothyroid patients. Values for patients receiving USP thyroid. Am J Dis Child 1980; 134:16-8.

30. DeGroot LJ, Larsen PR, Hennemann G. In Chapter 9, The Thyroid and its Diseases. 6th ed. Philadelphia:Churchill Livingstone, 1995.

31. Canaris GJ, Manowitz NR, Mayor G, Ridgway EC. The Colorado thyroid disease prevalence study. Arch Intern Med 2000; 160:526-34.

32. Ebeling PR. Endocrine Society of Australia Position Statement on Dessicated Thyroid or Thyroid Extract [online]. Available at: www.endocrinesociety.org.au Accessed December 6, 2012.

33. Fenwick EH. The diuretic action of fresh thyroid juice. Br Med J 1891; 2:798-9.

34. Karmisholt J, Andersen S, Laurberg P. Weight loss after therapy of hypothyroidism is mainly caused by excretion of excess body water associated with myxedema. J Clin Endocrinol Metab 2011; 96:E99-103.

35. Reinehr T. Obesity and thyroid function. Mol Cell Endocrinol 2010; 316:165-71.

36. Pearce EN. Thyroid hormone and obesity. Curr Opin Endocrinol Diabetes Obes 2012; 19:408-13.

37. Wolman SI, Sheppard H, Fern M, Waterlow JC. The effect of triiodothyronine (T3) on protein turnover and metabolic rate. Int J Obes 1985;9:459-63.

38. Abraham RR, Densem JW, Davies P, Davie MW, Wynn V. The effects of triiodothyronine on energy expenditure, nitrogen balance and rates of weight and fat loss in obese patients during prolonged calorie restriction. Int J Obes 1985; 9:433-42.

39. Brennan MD, Powell C, Kaufman KR, et al. The impact of overt and subclinical hypothyroidism on skeletal muscle. Thyroid 2006; 16:375-80.

40. Kaptein EM, Beale E, Chan LS. Thyroid hormone therapy for obesity and non-thyroidal illnesses: a systemic review. J Clin Endocrinol Metab 2009; 94:3663-75.

41. Hage MP, Azar ST. The link between thyroid function and depression. J Thyroid Res 2012; 2012:590648 Epub ahead of print.

42. Cooper-Kazaz R. Lerer B. Efficacy and safety of triiodothyronine supplementation in patients with major depressive disorder treated with specific serotonin reuptake inhibitors. Int J Neuropsychopharmacol 2008; 11:685-99.

43. Garlow SJ, Dunlop BW, Ninan PT, Nemeroff CB. The combination of triidothyronine (T3) and sertaline is not superior to sertraline monotherapy in the treatment of major depressive disorder. J Psychiatr Res 2012; 46:1406-13.

44.Cooper-Kazaz R, van der Deure WM, Medici M, et al. Preliminary evidence that a functional polymorphism in type 1 deiodinase is associated with enhanced potentiation of the antidepressant effect of sertraline by triiodothyronine. J Affect Dis 2009; 116:113-6.

45. Brent GA, Hershman JM. Thyroxine therapy in patients with severe nonthyroidal illness and low serum thyroxine concentration. J Clin Endocrinol Metab 1986; 63:1-8.

46. Klemperer JD. Thyroid hormone and cardiac surgery. Thyroid 2002; 12:517-21.

47. Cooper DK, Novitzky D, Wicomb WN, et al. A review of studies relating to thyroid hormone therapy in brain-dead organ donors. Front Biosci 2009; 1:3750-70

48. Powner DJ, Hernandez M. A review of thyroid hormone administration during adult donor care. Prog Transplant 2005; 15:202-7.

49. American Thyroid Association statement on "Wilson's syndrome". Posted May 24, 2005 [online]. Available at: www.thyroid.org Accessed December 6, 2012.

50. Mackowiak PA, Wasserman SS, Levine MM. A critical appraisal of 98.6 degrees $F$, the upper limit of the normal body temperature, and other legacies of Carl Reinhold August Wunderlich. JAMA 1992; 268:1578-80. 